\title{
Kinetic Model for Anaerobic Digestion of Distillery Spent Wash
}

\author{
Pooja Sharma*, Uttam Kumar Ghosh, Amiya Kumar Ray \\ Department of Polymer and Process Engineering, Indian Institute of Technology Roorkee, Roorkee, India
}

\section{Email address:}

sharma_poojas@rediffmail.com (P. Sharma), iitr.poojas@gmail.com (P. Sharma), ghoshuk_iitr@yahoo.com (U. K. Ghosh), amiyakumarray@gmail.com (A. K. Ray)

*Corresponding author

\section{To cite this article:}

Pooja Sharma, Uttam Kumar Ghosh, Amiya Kumar Ray. Kinetic Model for Anaerobic Digestion of Distillery Spent Wash. American Journal of Chemical Engineering. Vol. 4, No. 6, 2016, pp. 139-146. doi: 10.11648/j.ajche.20160406.11

Received: July 21, 2016; Accepted: August 2, 2016; Published: November 15, 2016

\begin{abstract}
Kinetic studies were carried out for anaerobic digestion of distillery spent wash considering growth kinetic models due to Monod and Contois. The kinetic parameters were predicted with the help of previously published experimental data for anaerobically treated distillery spent wash. The digester was operated at seven different values of loading rates ranging between 0.954 to $2.459 \mathrm{gCOD} / \mathrm{L} /$ day. Maximum specific growth rate and maximum specific substrate utilization rate for Monod model have been predicted as of the order of $0.153 \mathrm{~g} / \mathrm{g} /$ day $\left(\mu_{M}^{A M}\right)$ and $3.06 \mathrm{~g} / \mathrm{g} /$ day $\left(k^{A M}\right)$, respectively, and those for Contois kinetic model were found to be $0.140 \mathrm{~g} / \mathrm{g} / \mathrm{day}\left(\mu_{M}^{A M}\right)$ and $0.421 \mathrm{~g} / \mathrm{g} / \mathrm{day}\left(k_{C}^{A M}\right)$, respectively. However, for both the models the decay rate coefficient, $D^{A M}$ was calculated as $0.0131 \mathrm{~g} / \mathrm{g} / \mathrm{day}$. The estimated value of empirical constant $(B)$ in Contois model was found to be order of 0.699 (dimensionless). The deviation of model predicted values from experimental results has been compared. Sensitivity analysis of the developed models was carried out by considering $10 \%$ increase in the values of both $\mu_{M}^{A M}$ and $D^{A M}$.
\end{abstract}

Keywords: Kinetic Modelling, Anaerobic Digester, Distillery Spent Wash, Monod Kinetics, Contois Kinetics and Sensitivity Analysis

\section{Introduction}

Anaerobic digestion process is used to treat wastewater generated from various municipal and industrial activities and also sludge generated from aerobic processes [1, 2]. This process is further classified into suspended growth (contact process, sequencing batch reactor, continuous stirred tank reactor, etc.) and attached growth (upflow packed bed reactor, upflow anaerobic expanded bed reactor, fluidized bed reactor, downflow attached growth anaerobic processes, etc.) biological wastewater treatment processes. Various microbial growth kinetic models such as Monod, Contois, Chen and Hashimoto, Haldane, Mosey, etc., have been developed by various investigators to describe the performance of anaerobic digester [3]. These expressions are required in developing total continuity equations for describing the performance of anaerobic digester and to predict behavior under dynamic conditions. Monod kinetic model, which is based on Michaelis-Menten equation, gives relationship between specific growth rate and growth limiting substrate in dissolved form [3, 4] whereas, Contois model is a functional relationship between specific growth rate and concentrations of substrate both at the inlet and the outlet of the digester [3,5]. Chen and Hashimoto kinetic model is concerned with substrate utilization and methane production [5].

Distillery wastewater generated from distillation of the alcohol (rectified spirit from analyzer column) which in fact, vary in composition depending on the kind of raw materials and type of fermentation process. In India fermentation is accomplished with cane molasses using yeast cell and Saccharomyces cerevisiae. The distillery spent wash is the waste generated from distillery based on cane molasses as 
raw material. The data reported on kinetic parameters of anaerobic treatment of distillery wastes including vinasses (waste generated after fermentation of molasses) are plenty [6-10]. However, microbial kinetic parameters required for design applications and estimation of treatment efficiency for digestion of spent wash based on cane molasses as raw material are scanty. Not any studies reported till date which describes the microbial growth kinetic coefficients for distillery waste based on Contois model for design applications. Large volume of data related to anaerobic degradation kinetics of sewage sludge and other wastes are available in literature $[7,8]$.

The predicted values of the microbial growth kinetic parameters for different kind of wastes vary from waste to waste and depend on the source of waste generation, process conditions, the digester used for treatment and nature of inhibitory compounds present in the wastes. Study carried out for microbial growth kinetics for different types of wastes in complete mixed anaerobic digester operated at mesophilic temperature range. The kinetic parameters were estimated on the basis of mathematical modelling (by developing steady state model) for mixed community of microorganisms based on Monod kinetic model. These are discussed in the following paragraphs:

Bello-Mendoza et al. [1] reported the kinetic coefficient values for sewage sludge consist of maximum specific substrate utilization rate $(8.0 \mathrm{~g} / \mathrm{g} /$ day $)$, yield coefficient $(0.3$ $\mathrm{g} / \mathrm{g})$, decay rate coefficients for acidogens $\left(0.1\right.$ day $\left.^{-1}\right)$ and for methanogens $\left(0.015 \mathrm{day}^{-1}\right)$. Hu et al. [5] determined the kinetic coefficients for anaerobic contact digester treating ice-cream wastewater which comprised of yield coefficient $(0.2116 \mathrm{~g} / \mathrm{g})$, empirical constant based on Contois model $(0.4818)$ and half velocity coefficient $(0.4028 \mathrm{~g} / \mathrm{L})$. The specific bacterial growth rates based on Monod as well as Contois model were found $\left(0.7844\right.$ day $\left.^{-1}\right)$ and $\left(0.9207\right.$ day $\left.^{-1}\right)$, respectively. For cattle waste the above kinetic coefficient was found to be order of $0.37 \mathrm{~L} / \mathrm{g}, 0.30 \mathrm{~g} / \mathrm{L}$ and $0.25 \mathrm{day}^{-1}$, respectively. Borja et al. [8] estimated that the yield coefficient of microbial species degrading brewery wastewater is $0.08 \mathrm{~g} / \mathrm{g}$ and specific substrate utilization rate $0.045 \mathrm{~g} / \mathrm{g} /$ day. Based on Chen-Hashimoto model, Jimenez et al. [6] investigated on kinetics for untreated and previously treated vinasses where maximum production rate of methane was found to be $1.27 \mathrm{~L} /$ day and $0.891 \mathrm{~L} /$ day, respectively. The specific growth rate and half velocity coefficient for untreated waste were $0.87 \mathrm{day}^{-1}$ and $0.90 \mathrm{~g} / \mathrm{L}$, respectively, and 0.09 day $^{-1}$ and $0.13 \mathrm{~g} / \mathrm{L}$, respectively, for treated vinasses.

The aim of the present study is to predict the kinetic coefficient for distillery spent wash using the data reported by Borja et al. [11] for the developed models based on Monod and Contois kinetics and to compare them to describe the performance of complete mix anaerobic digester.

\section{Model Development}

Steady state model has been developed for the estimation of the kinetic parameters for distillery spent wash based on sugar cane molasses as raw material. The experimental data was published in literature due to Borja et al. [11] was undertaken. The experiments were conducted under mesophilic conditions in continuous complete mix digester of volume $2.35 \mathrm{~L}$ operated at seven different loading rates ranging from 0.954 $\mathrm{g} / \mathrm{L}$ /day to $2.4589 \mathrm{~g} / \mathrm{L} /$ day. The influent substrate concentration fed to digester in the above experiment had COD level of $4.7 \mathrm{~g} / \mathrm{L}$. The laboratory data for spent wash could give the process efficiency in terms of COD removal and rate of methane production. This data fails to describe the inside conditions of the digester such as microbial kinetics, the growth and decay rate terms, specific growth rate and utilization rate of substrate by micro-organisms.

Mass balance equations have been applied across complete mix suspended growth anaerobic digester to derive a new set of equations based on organic loading rate variation. The microbial kinetics has been described by two steady-state models due to Monod as well as Contois. The developed kinetic rate expressions are based on the concepts proposed earlier by Tchobanoglous et al. [4]; Hu et al. [5].

\subsection{Kinetic Modelling of Anaerobic Digester Based on Monod Kinetics}

\subsubsection{Mass Balance Equation for Spent Wash}

Flow rate of raw substrate into the digester - Flow rate of substrate at the outlet of digester \pm Net utilization rate of substrate $=$ Rate of accumulation of substrate

$$
\begin{aligned}
& \text { Flow rate of raw Flow rate of Net utilization Rate of } \\
& \text { substrate into - } \quad \text { substrate at the } \pm \text { rate of }=\text { accumulation } \\
& \text { the digester } \quad \text { outlet of digester substrate } \quad \text { of substrate } \\
& \frac{Q}{V} S_{0}^{A M}-\frac{Q}{V} S^{A M} \pm r_{S U}^{A M}=\frac{d S^{A M}}{d t}
\end{aligned}
$$

Under steady-state condition, $t=0 ; \frac{d S^{A M}}{d t}=0$

Substrate utilization rate based on Michaelis-Menten equation,

$$
r_{S U}^{A M}=\left(-\frac{k^{A M} X^{A M} S^{A M}}{K_{S}^{A M}+S^{A M}}\right)
$$

Therefore, Eq. (1) may be written as

$$
O L R-\frac{1}{H R T} S^{A M}=\left(\frac{Y^{A M}}{Y^{A M}}\right)\left(\frac{k^{A M} X^{A M} S^{A M}}{K_{S}^{A M}+S^{A M}}\right)
$$

Based on Monod growth kinetics

$$
\mu_{M}^{A M}=k^{A M} Y^{A M} \text { and } \mu^{A M}=\frac{k^{A M} Y^{A M} S^{A M}}{K_{S}^{A M}+S^{A M}}
$$

and Eq. (2) can be written as follow 


$$
\frac{H R T^{*} X^{A M}}{O L R^{*} H R T-S^{A M}}=\left(\frac{K_{S}^{A M}}{k^{A M}}\right)\left(\frac{1}{S^{A M}}\right)+\left(\frac{1}{k^{A M}}\right)
$$

Now with the help of laboratory data for spent wash and by linear regression method the kinetic parameters $k^{A M}$ and $K_{S}^{A M}$ can be evaluated from Eq. (3).

\subsubsection{Mass Balance Equation for Biomass}

Inflow - Outflow \pm Net growth rate= accumulation

$$
\frac{Q}{V} X_{0}^{A M}-\frac{Q}{V} X^{A M} \pm r_{g}^{A M}=\frac{d X^{A M}}{d t}
$$

Under steady-state conditions $\frac{d X^{A M}}{d t}=0 ; X_{0}^{A M}=0$

and assuming the concentration of biomass in the raw spent wash feed to the digester is negligible, Eq. (4) becomes

$$
\frac{1}{H R T}=\frac{r_{g}^{A M}}{X^{A M}}=\mu^{A M}
$$

Use of Monod kinetic model yields

$$
\frac{Q}{V} X^{A M}+D^{A M} X^{A M}=\left(Y^{A M}\right)\left(\frac{k^{A M} X^{A M} S^{A M}}{K_{S}^{A M}+S^{A M}}\right)
$$

With the help of Eq. (6) and also from Eq. (2), the developed equation can be written as

$$
\left(\frac{1}{H R T}\right)\left(\frac{1}{Y^{A M}}\right)+\left(\frac{D^{A M}}{Y^{A M}}\right)=\left(\frac{O L R^{*} H R T-S^{A M}}{H R T^{*} X^{A M}}\right)
$$

With the help of laboratory data kinetic parameters $D^{A M}$ and $Y^{A M}$ can be predicted by linear regression

\subsection{Kinetic Modelling of Anaerobic Digester Based on Contois Kinetics}

Now, from Eq. (6) using Contois model [3] under steady state conditions the equation can be written as

$$
\frac{1+D^{A M} H R T}{H R T}=\mu^{A M}, \mu^{A M}=\frac{k_{C}^{A M} Y^{A M} S^{A M}}{B^{*} X^{A M}+S^{A M}}
$$

From Eq. (8)

$$
\frac{H R T^{*} Y^{A M}}{1+H R T^{*} D^{A M}}=\left(\frac{B}{k_{C}^{A M}}\right)\left(\frac{X^{A M}}{S^{A M}}\right)+\frac{1}{k_{C}^{A M}}
$$

Laboratory data can be used to predict kinetic parameters $B$ and $k_{C}^{A M}$ by regression analysis using Eq. (9).

\section{Results and Discussion Based on Distillery Spent Wash}

\subsection{Evaluation of Kinetic Parameters for Spent Wash}

The kinetic parameters for Monod as well as those from Contois model for distillery spent wash have been estimated through the developed model as given in Section 2 and also with the distillery data mentioned in previously published research work due to Borja et al. [11]. The developed model (Eq. (3), Eq. (7) and Eq. (9)) are used to evaluate the microbial kinetic rates.

Figure 1 has been plotted between $\frac{H R T^{*} X^{A M}}{O L R^{*} H R T-S^{A M}}$ as a function of $\frac{1}{S^{A M}}$ for the estimation of kinetic parameters $k^{A M}$ and $K_{S}^{A M}$ from Eq. (3) for spent wash based on Monod kinetics. From the slope of the straight line and the intercept the values of $K_{S}^{A M}$ and $k^{A M}$, respectively, can be predicted.

\section{MONOD KINETIC MODEL}

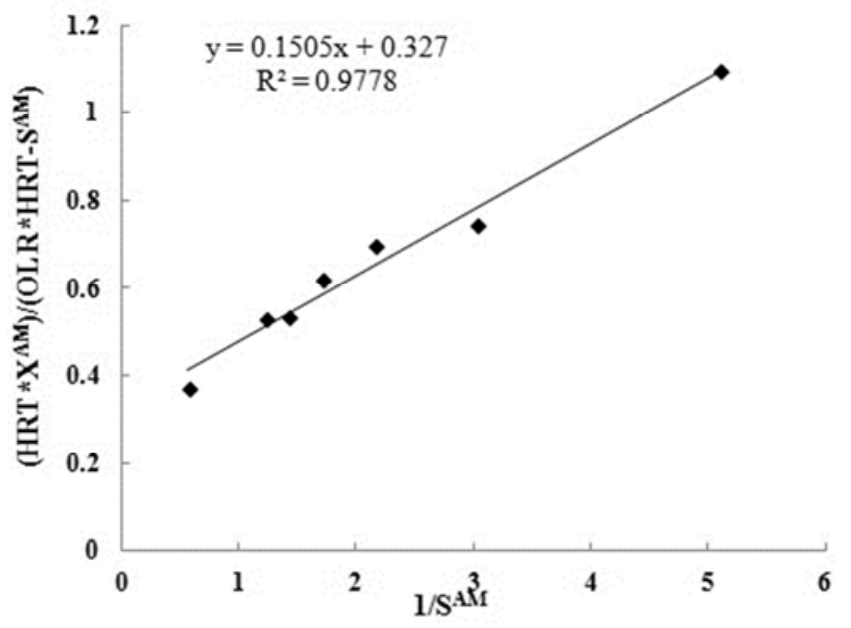

Figure 1. Estimation of saturation constant, $K_{S}^{A M}$, and maximum specific substrate utilization rate, $k^{A M}$, for distillery spent wash based on Monod growth kinetic model.

Figure 2 has been drawn $\frac{O L R^{*} H R T-S^{A M}}{H R T^{*} X^{A M}}$ against $\frac{1}{H R T}$ for the estimation of $Y^{A M}$ and $D^{A M}$ as given in Eq. (7). The values of $D^{A M}$ and $Y^{A M}$ can be evaluated by least square fit. 


\section{MONOD KINETIC MODEL}

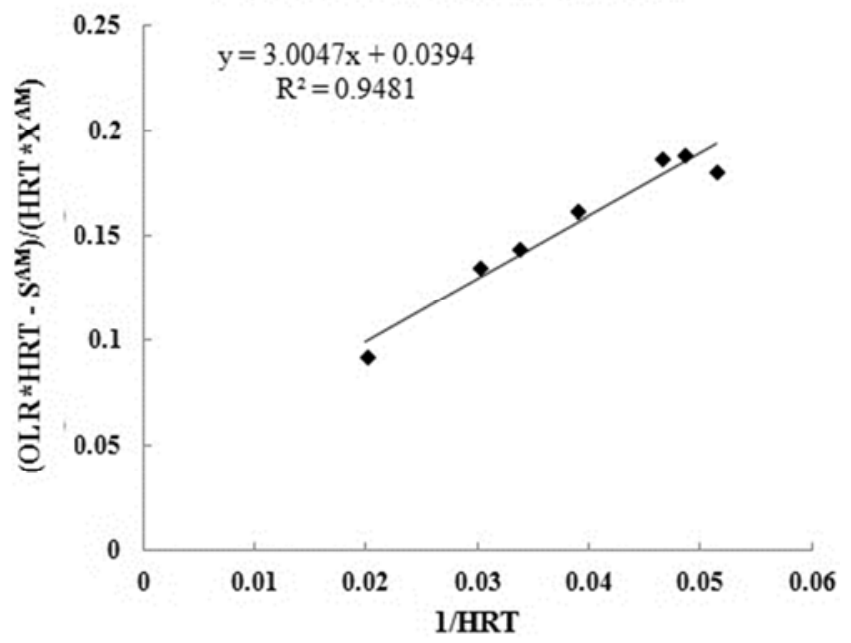

Figure 2. Estimation of decay rate coefficient, $D^{A M}$, and synthesis yield coefficient, $Y^{A M}$, for distillery spent wash based on Monod growth kinetic model.

For the prediction of kinetic parameters $B$ and $k_{C}^{A M}$ based on Contois growth kinetics from Eq. (9), plot $\frac{X^{A M}}{S^{A M}}$ versus $\frac{H R T^{*} Y^{A M}}{1+H R T^{*} D^{A M}}$ as shown in Figure 3. With the help of linear regression method the values of $B$ and $k_{C}^{A M}$ are predicted.

\section{CONTOIS KINETIC MODEL}

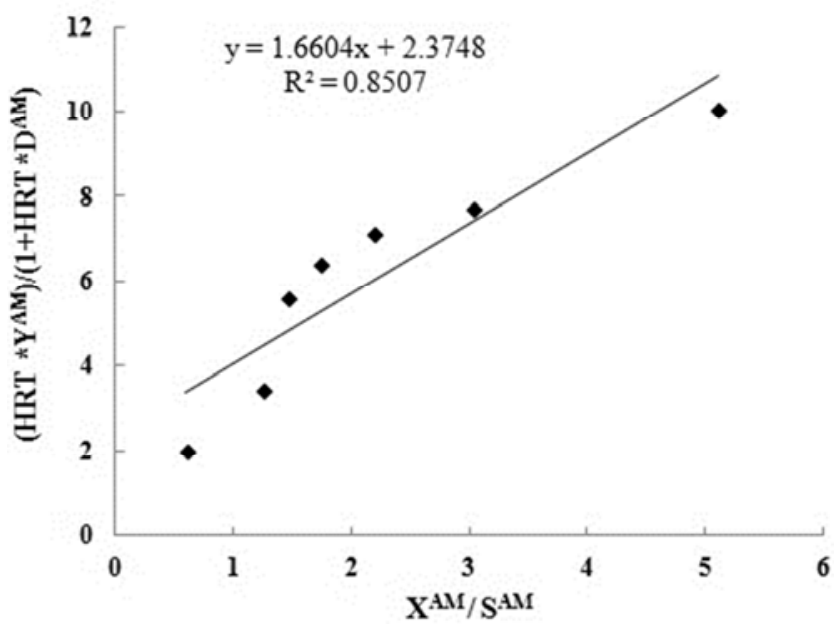

Figure 3. Estimation of maximum specific substrate utilization rate, ${ }_{C}^{A M}$, and empirical constant, $B$, for distillery spent wash based on Contois kinetic model.

The estimated kinetic parameters for spent wash based on model equations are compared with the predicted values for different kinds of wastes [4, 5, 12-15] as mentioned in Table 1. The evaluated kinetic parameters as given in Table 1 are in close agreement with the range of microbial kinetic parameters based on modelling for different kind of wastes.

Table 1. Model predicted values of kinetic parameters for different kind of wastes.

\begin{tabular}{|c|c|c|c|c|c|}
\hline $\begin{array}{l}\text { Kinetic } \\
\text { Coefficient }\end{array}$ & $\begin{array}{l}\text { Distillery Spent wash } \\
\text { (present study) }\end{array}$ & $\begin{array}{l}\text { Ice-cream wastewater } \\
\text { Hu et al. [5] }\end{array}$ & $\begin{array}{l}\text { Distillery wastewater } \\
\text { Prakash } \text { et al. }[12]\end{array}$ & $\begin{array}{l}\text { Municipal solid waste } \\
\text { Nwabanne et al. }[13]\end{array}$ & $\begin{array}{l}\text { Sewage sludge } \\
\text { Tchobanoglous et al. [4] }\end{array}$ \\
\hline \multirow{2}{*}{$\mu_{M}^{A M}(\mathrm{~g} / \mathrm{g} / \mathrm{day})$} & $\begin{array}{l}\text { Monod } \\
0.153\end{array}$ & $\begin{array}{l}\text { Monod } \\
0.7844\end{array}$ & 1.56 & 0.53 & $\begin{array}{l}0.35 \\
(0.30-0.38)\end{array}$ \\
\hline & $\begin{array}{l}\text { Contois } \\
0.140\end{array}$ & $\begin{array}{l}\text { Contois } \\
0.9297\end{array}$ & - & - & - \\
\hline$Y^{A M} \quad(\mathrm{~g} / \mathrm{g})$ & 0.3328 & 0.2116 & 0.5 & 0.367 & $\begin{array}{l}0.08 \\
(0.05-0.1)\end{array}$ \\
\hline$D^{A M}$ (g/g/day) & 0.0131 & 0.0131 & 0.05 & 0.038 & $\begin{array}{l}0.03 \\
(0.002-0.04)\end{array}$ \\
\hline$K_{S}^{A M}(\mathrm{~g} / \mathrm{L})$ & 0.4605 & 0.4028 & 0.024 & 0.21 & $\begin{array}{l}0.16 \\
(0.06-0.2)\end{array}$ \\
\hline$k^{A M}(\mathrm{~g} / \mathrm{g} /$ day $)$ & 3.06 & 3.7 & 3.125 & 0.144 & - \\
\hline$k_{C}^{A M}(\mathrm{~g} / \mathrm{g} /$ day $)$ & 0.421 & 4.39 & - & - & - \\
\hline$B$ (Dimensionless) & 0.699 & 0.4818 & & & \\
\hline
\end{tabular}

\subsection{Deviation of the Model Predicted Values of, $S^{A M}$, from Experimental Data}

The formulae used for prediction of effluent substrate concentration ( $S^{A M}$ ) based on Monod growth kinetic model was obtained by rearranging Eq. (3) and Eq. (9), respectively.

The deviation of model predicted effluent substrate concentration ( $S^{A M}$ ) from the experimental values due to Borja et al. [8] for both Monod and Contois models has been plotted with the help of estimated kinetic parameters. These are shown in Figure 4 based on Monod model whereas
Figure 5 is plotted for Contois model. From Figures 4 and Figure 5 , the $\mathrm{R}^{2}$ values are found of the order of 0.8751 for Monod whereas the same for Contois model 0.9323. The percentage deviation for both the models is found below $12.5 \%$. However, it is observed that Contois model fits the experimental data better for spent wash, indicating its superiority over the other models. Hence, model developed based on Contois model can suitability be used for spent wash. 
MONOD KINETIC MODEL

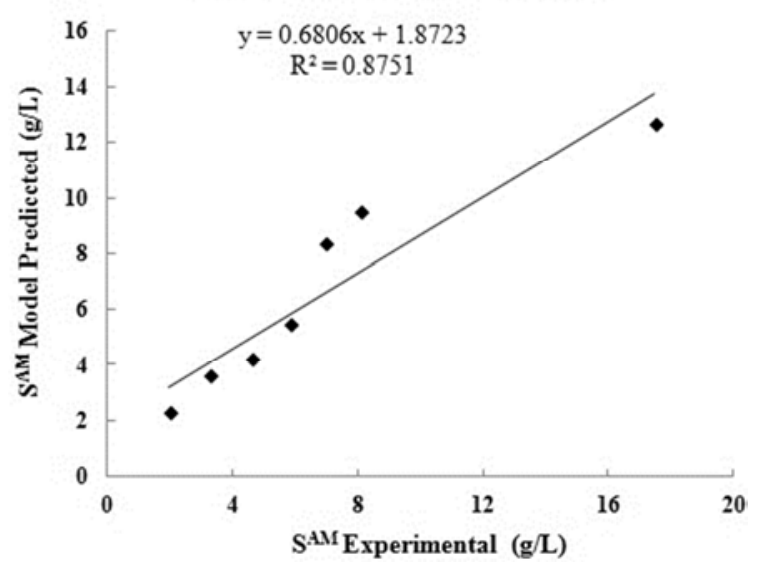

Figure 4. Comparison between the model predicted values of $S^{A M}$ based on Monod model with the experimental values for distillery spent wash based on Monod kinetics.

\section{CONTOIS KINETIC MODEL}

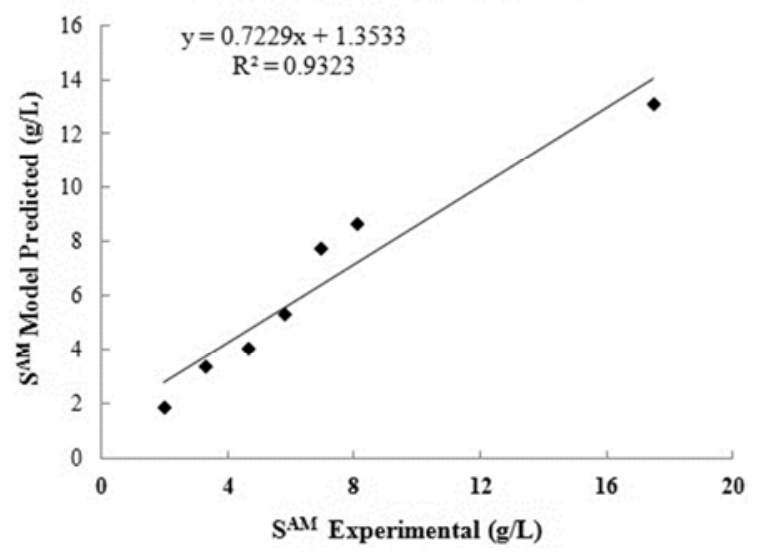

Figure 5. Comparison between model predicted values of $S^{A M}$ with the experimental results for distillery spent wash based on Contois kinetic model.

\subsection{Sensitivity Analysis for Spent Wash}

Sensitivity analysis is essential for analyzing accuracy of the data whether it is experimental or model predicted. Therefore, attempts have been made to carry out the sensitivity analysis by varying the values of maximum specific growth rate coefficient, $\mu_{M}^{A M}$, and decay rate coefficient, $D^{A M}$, for both the models (Monod and Contois) and their effects on COD concentration in effluent $\left(S^{A M}\right)$. With the help of formulae (based on Eq. (3) and Eq. (9)), the values for $S^{A M}$ for both the models are estimated. Figure 6 through Figure 9 represent the model predicted $S^{A M}$ values as function of HRT for Monod model and organic loading rate (OLR) for Contois model. The $S^{A M}$ values in Contois model are predicted by plotting it against OLR instead of HRT because the effluent substrate concentration in Contois model is dependent upon the influent substrate concentration feed to the digester.

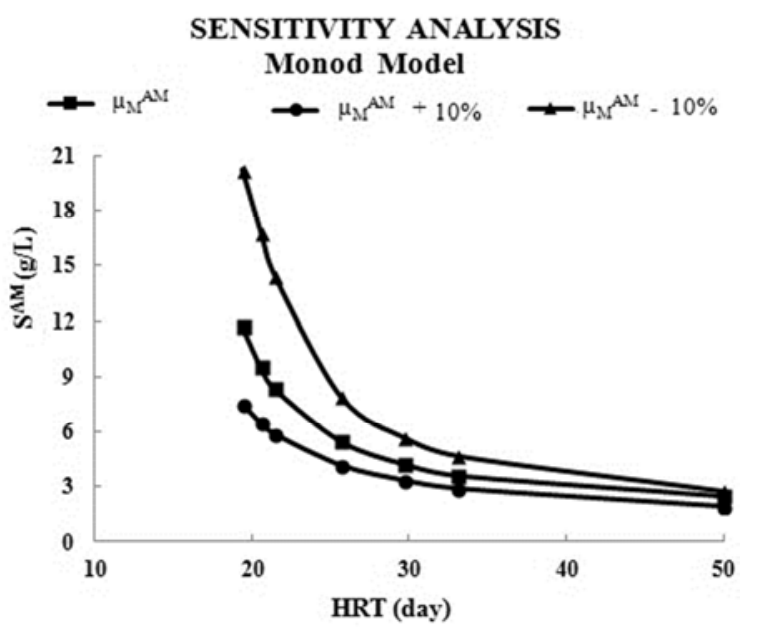

Figure 6. Sensitivity analysis of $\mu_{M}^{A M}$ value and its effect on effluent substrate concentration, $S^{A M}$ as function of HRT for distillery spent wash based on Monod model.

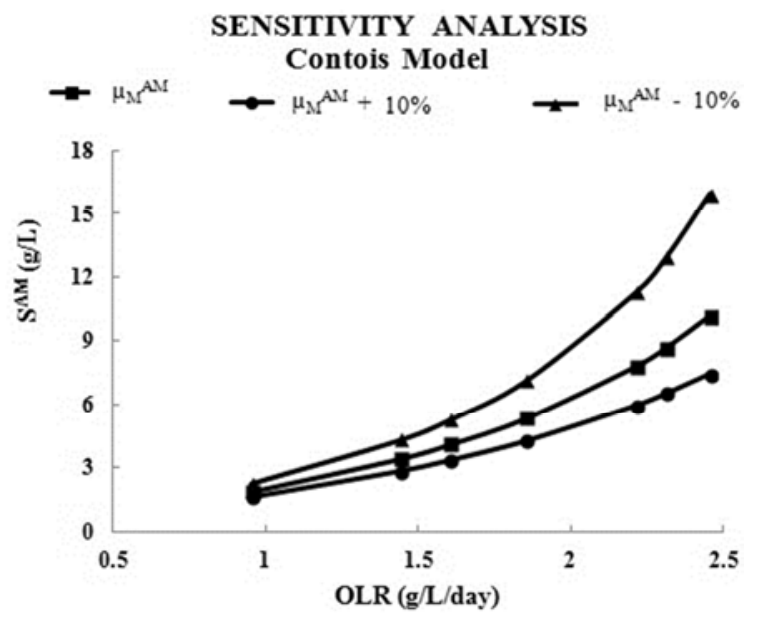

Figure 7. Sensitivity analysis of $\mu_{M}^{A M}$ and its influence on effluent substrate concentration, $S^{A M}$ as function of OLR for distillery spent wash based on Contois model.

The sensitivity of microbial growth kinetic term $\mu_{M}^{A M}$ on process performance in terms of COD removal has been predicted by considering $10 \%$ variation in $\mu_{M}^{A M}$ value for both the models. If it is assumed that the process is operated under steady state conditions, there is not any inhibitory effect noticed on microbial growth kinetics [16-18]. At steady state conditions, based on Monod model 10\% increase in the value of $\mu_{M}^{A M}$ as shown in Figure 6 is found to decrease with the COD in effluent resulting in higher efficiency. From the Figure 6 it is also observed that if the growth kinetics is assumed to be inhibited under any shock loading condition (10\% decrease in $\mu_{M}^{A M}$ ). Under this situation, lower COD removal efficiency is obtained as compared to other two cases $(10 \%$ increase in $\mu_{M}^{A M}$ and at constant value of $\mu_{M}^{A M}$ ). At the hydraulic retention time of 50 day, COD removal percentage is found to be $94.88 \%$. Increasing $\mu_{M}^{A M}$ by $10 \%$ increase of percent COD 
removal from $94.88 \%$ to $96.02 \%$ has been observed. Further decreasing $\mu_{M}^{A M}$ by $10 \%$ decreases in percentage COD removal from $94.88 \%$ to $94.18 \%$. At the retention time of 20.6 day, increase in value of $\mu_{M}^{A M}$ by $10 \%$, COD removal increases from $80.15 \%$ to $86.51 \%$, whereas by decreasing $\mu_{M}^{A M}$ by $10 \%$, reduction in percent COD removal occurred from $80.15 \%$ to $62.78 \%$.

The same condition has been applied for Contois model and is plotted in Figure 7. At the OLR of $1.606 \mathrm{~g} / \mathrm{L} /$ day, increasing $\mu_{M}^{A M}$ value by $10 \%$ increases percent COD removal from $91.39 \%$ to $92.98 \%$, whereas decrease in $\mu_{M}^{A M}$ by $10 \%$ decreases the same from $91.39 \%$ to $88.91 \%$. From this study it can be concluded that if the microbial growth rate decreases there is significant effect on process performance in terms of COD removal. Again simulation studies have been carried out considering the combined effect of both $\mu_{M}^{A M}$ as well as $D^{A M}$ on COD removal by varying $10 \%$ of the values as shown in Figure 8 and Figure 9.

Figure 8 has been plotted between $S^{A M}$ as a function of HRT whereas Figure 9 as a function of OLR. It is well known fact that as the growth rate of microbial species increases there is also simultaneous increase in decay rate of microorganisms. By considering these aspects process performance has been predicted by considering combined effect of both the variables. As shown in Figure 8 based on Monod model if both the kinetic parameters increases by $10 \%$, the percent COD removal increases from $88.61 \%$ to $90.46 \%$ at the retention time of 25.7 day. Reduction in percent COD removal from $88.61 \%$ to $85.13 \%$ has been observed at the same retention time on decreasing both the variables by $10 \%$. Figure 9 represents the variation in terms of $S^{A M}$ as function of OLR based on Contois model. If the digester is operated at OLR of $1.856 \mathrm{~g} / \mathrm{L} /$ day, the combined effect of both the parameters by increasing their values at $10 \%$ resulted in increase in percentage COD removal from $88.79 \%$ to $90.63 \%$. Further, it is also noticed a reduction in percentage from $90.63 \%$ to $86.13 \%$ by decreasing both the parameters by $10 \%$.

By performing sensitivity analysis, the importance of the process variables and its effect on process performance can be evaluated. Also methods are to be devised for enhanced performance by controlling the inhibitory substances that effect microbial survival.

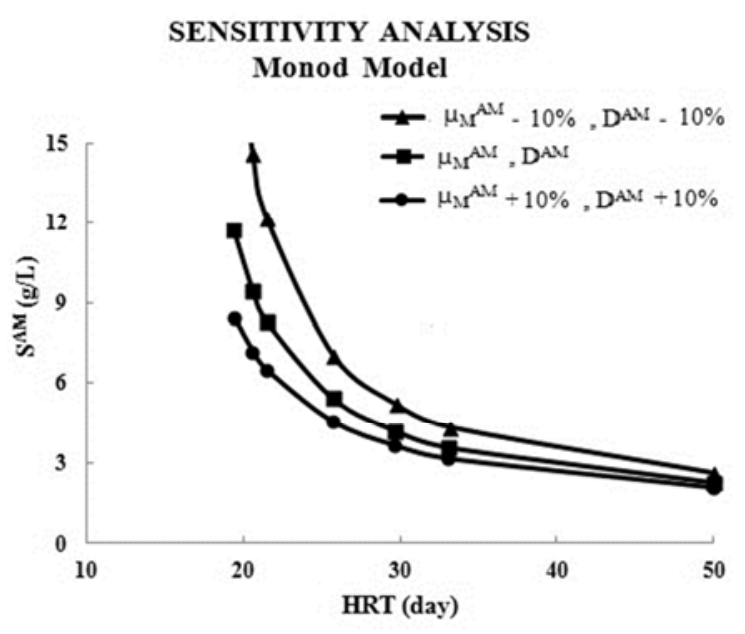

Figure 8. Sensitivity analysis of $\mu_{M}^{A M}$ and $D^{A M}$, and their combined effect on $S^{A M}$ as function of HRT for distillery spent wash based on Monod model.

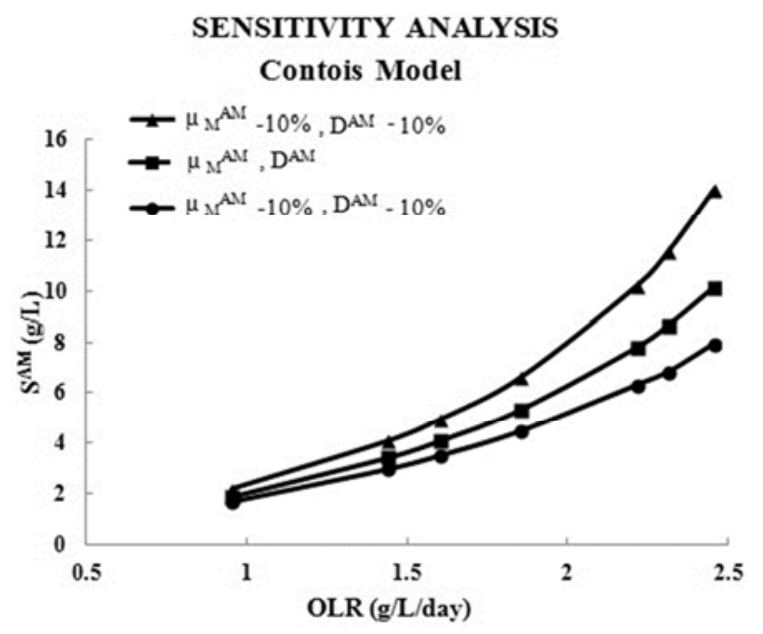

Figure 9. Sensitivity analysis of $\mu_{M}^{A M}$ and $D^{A M}$, and their combined effect on $S^{A M}$ as function of OLR for distillery spent wash based on Contois model.

Table 2 represents the confidence interval level of the values predicted from model equations. Student t-distribution method has been adopted for the above estimation [19, 20]. Three different probability levels, $90 \%, 95 \%$ and $99 \%$ were selected for estimation of $S^{A M}$ values for both Monod as well as Contois model.

Table 2. Confidence interval for $S^{A M}$ from derived equations for distillery spent wash based on Monod as well as Contois growth kinetic models.

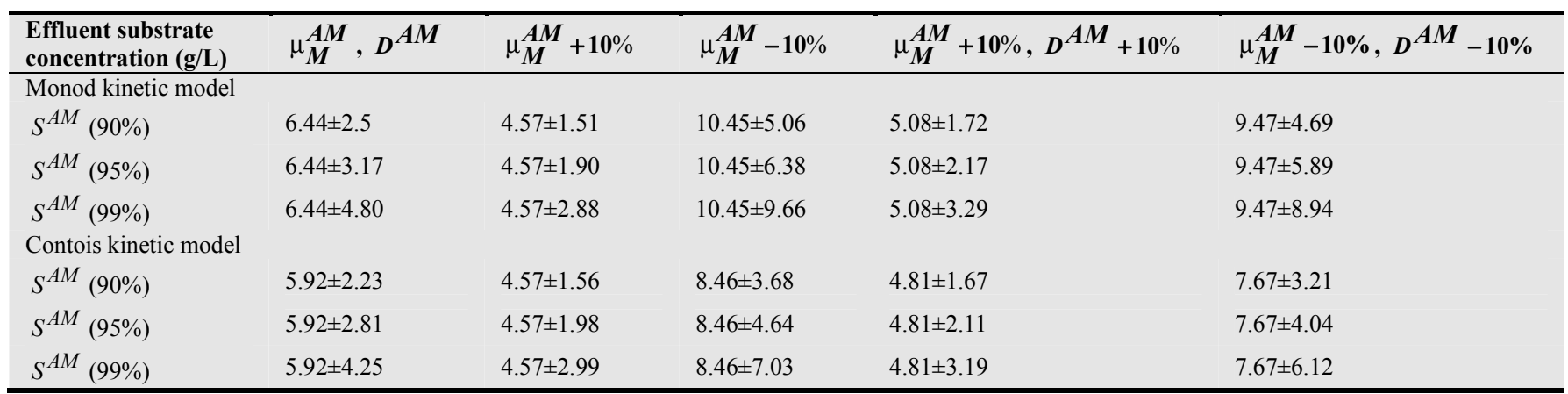




\section{Conclusions}

From the above analysis the following noteworthy conclusions can be drawn:

- Steady state model equation based on Contois model is found more suitable for analyzing performance of anaerobic digestion of spent wash.

- For spent wash the developed steady state model equations fits well for analyzing performance of anaerobic digestion. Statistical analysis reveals that Contois model is found to be more suitable (with higher $\mathrm{R}^{2}$ value of 0.9323 ) in this type of waste. Confidence interval for $S^{A M}$ at $95 \%$ for both Monod as well as Contois based models was found $6.44 \pm 3.17$ and $5.92 \pm 2.81$, respectively.

- Sensitivity analysis for spent wash also explains well the impact of kinetic parameters on process performance. Decrease in COD removal efficiency has been observed at lower specific growth rate of microorganisms.

- The predicted values of maximum specific substrate utilization rate $\left(\mu_{M}^{A M}\right)$ for both Monod as well as Contois models for distillery spent wash is lower as compared to that of vinasses. This indicates the presence of inhibitory substances in distillery spent wash that inhibit growth kinetics of microbial species.

\section{Acknowledgement}

This work has been supported by Ministry of Human Resources and Development (MHRD), Government of India.

\section{Nomenclature}

$S_{0}^{A M}$

$S^{A M}$

$r_{S U}^{A M}$

$Y^{A M}$

$k^{A M}$

$k_{C}^{A M}$

$K_{S}^{A M}$

$\mu_{M}^{A M}$

$\mu^{A M}$

$\mathrm{B}$

$X_{0}^{A M}$

$X^{A M}$

$r_{g}^{A M}$

$D^{A M}$
Influent substrate concentration $(\mathrm{g} / \mathrm{L})$

Effluent substrate concentration $(\mathrm{g} / \mathrm{L})$

Substrate utilization rate (g/L/day)

Synthesis yield coefficient $(\mathrm{g} / \mathrm{g})$

Maximum specific substrate utilization rate for

Monod kinetics (g/g/day)

Maximum specific substrate utilization rate for

Contois Kinetics (g/g/day)

Half velocity coefficient for Monod growth kinetics $(\mathrm{g} / \mathrm{L})$

Maximum specific bacterial growth rate (g/g/day)

Specific bacterial growth rate (g/g/day)

Contois kinetic constant (Dimensionless)

Influent biomass concentration $(\mathrm{g} / \mathrm{L})$

Effluent biomass concentration $(\mathrm{g} / \mathrm{L})$

Net biomass growth rate (g/L/day)

Decay coefficient (g/g/day)

$\begin{array}{ll}\text { OLR } & \text { Organic loading rate (g COD/L/day) } \\ H R T & \text { Hydraulic retention time (day) } \\ \mathrm{Q} & \text { Volumetric flow rate (L/day) } \\ \mathrm{V} & \text { Volume of digester (L) }\end{array}$

\section{References}

[1] R. Bello-Mendoza, P. N. Sharratt, Modelling the effects of imperfect mixing on the performance of anaerobic reactors of sewage sludge treatment, Journal of Chemical Technology and Biotechnology, 71 (1998) 121-130.

[2] H. N. Gavala, I. Angelidaki, B. K. Ahring, Kinetics and modeling of anaerobic digestion process, Advances in Biochemical Engineering/Biotechnology, 81 (2003) 57-93.

[3] J. E. Bailey, D. F. Ollis, Biochemical Engineering Fundamentals, $2^{\text {nd }}$ Ed., McGraw-Hill Book Company, Hamburg, 391-394, 943-956 (1987).

[4] G. Tchobanoglous, F. L. Burton, H. D. Stensel, Wastewater Engineering: Treatment and Reuse, $4^{\text {th }}$ Ed., McGraw-Hill Education (India) Private Limited, New Delhi, 588-601, 629635, 999-1005 (2003).

[5] W. C. Hu, K. Thayanithy, C. F. Forster, A kinetic study of the anaerobic digestion of ice-cream wastewater, Process Biochemistry, 37 (2002) 965-971.

[6] A. Jimenez, R. Borja, A. Martin, F. Raposo, Kinetic analysis of the anaerobic digestion of untreated vinasses and vinasses previously treated with Penicillium decumbens, Journal of Environmental Management, 80 (2006) 303-310.

[7] D. Sales, M. Valcarcel, L. Romero, E. Martinez de la Ossa, Anaerobic digestion kinetics of wine-distilleries wastewaters, Journal of Chemical Technology and Biotechnology, 45 (1989) 147-162.

[8] R. Borja, A. Martin, M. Luque, M. M. Duran, kinetic study of anaerobic digestion of wine distillery wastewater, Process Biochemistry, 28 (1993) 83-90.

[9] R. Borja, A. Martin, M. M. Duran, M. Luque, V. Alonso, Kinetic study of anaerobic digestion of brewery wastewater, Process Biochemistry, 29 (1994) 645-650.

[10] R. Moletta, D. Verrier, G. Albagnac, Dynamic modelling of anaerobic digestion, Water Research, 20 (1986) 427-434.

[11] R. Borja, E. Sanchez, A. Martin, A. M. Jimenez, Kinetic behaviour of waste type rubber as microorganism support in an anaerobic digester treating cane molasses distillery slops, Bioprocess Engineering, 16 (1996) 17-23.

[12] N. B. Prakash, V. Sockan, V. S. Raju, Anaerobic digestion of distillery spent wash, ARPN Journal of Science and Technology, 4 (2014) 134-140.

[13] J. T. Nwabanne, O. D. Onukwuli, C. M. Ifeakandu, Biokinetics of anaerobic digestion of municipal waste, International Journal of Environmental Research, 3 (2004) 511-516.

[14] I. Lopez, M. Passeggi, L. Borzacconi, Variable kinetic approach to modelling an industrial waste anaerobic digester, Biochemical Engineering Journal, 96 (2015) 7-13. 
[15] S. Banerjee, A. Sirkar, Determination of kinetic parameters in anaerobic digestion process using distillery wastes - A mathematical approach, International Journal of Scientific and Research Publication, 2 (2012) 1-7.

[16] L. Yu, P. C. Wensel, J. Ma, S Chen, Mathematical modelling in anaerobic digestion, Bioremediation and Biodegradation, 4 (2013) 1-12.

[17] J. F. Andrews, Dynamic model for anaerobic digestion process, Journal of the Sanitary Engineering Division, 95 (1969) 285-310.
[18] J, F. Andrews, S. P. Graef, Dynamic modelling and simulation of the anaerobic digestion process, Advances in Chemistry, 105 (1971) 126-162.

[19] J. Neyman, Outline of a Theory of Statistical Estimation Based on the Classical Theory of Probability, Philosophical Transactions of the Royal Society A 236, 333-380 (1937).

[20] M. S. Peters, K. D. Timmerhaus, Plant Design and Economics for Chemical Engineers, $3^{\text {rd }}$ Ed., McGraw-Hill International Book Company, Kogakusha, 810-829 (1981). 